\title{
An Effect Etching Time on Structure Properties of Nano-Crystalline p-type Silicon
}

\author{
Hasan A. Hadi \\ Department of Physics, College of Education, University of Al-Mustansiriyah, Baghdad, Iraq \\ E-mail address: ha_yaba@yahoo.com
}

\begin{abstract}
This paper reports the influence of the etching time on structural characteristics of porous silicon manufactured by electrochemical etching (ECE) anodization p-type silicon wafers. Micro and nano-structural features of the samples are mainly investigated by XRD and AFM techniques. The morphological properties of PS layer such as nano-crystalline size, the structure aspect of PS layer and lattice constant have been investigated. Nanocrystals size (grain size) computing from XRD data (145 to 85$) \mathrm{nm}$ is resulting the increasing etching time.AFM investigations reveal increase in (RMS) roughness, Sz.(Ten Point height) and average diameter of the porous structure with increase in etching time.
\end{abstract}

Keywords: Porous Silicon; Electrochemical Etching (ECE); XRD; AFM

\section{INTRODUCTION}

Porous silicon has attracted much attention among technologists for developing optical and electronic devices [1]. One of the most important characteristics of the PS layers its very large and reactive internal surface so that, one should expect, that this internal surface would play an important role in those specific properties of PS layers which make this material so different from bulk one [2]. In all PS applications, information about the pore size and their distribution and surface chemistry and their dependence on the fabrication conditions plays decisive role. Correlation of observed physical properties with the morphology of PS films and the relationship between PS morphology and preparation parameters is necessary [3]. The properties of porous silicon structures are of increased importance for a fundamental understanding of nano systems as well as from a practical point of view to understand and control the materials fabrication processes [4]. In this paper, porous silicon layers were prepared on $\mathrm{p}$-Si single crystal wafers by a electrochemical etching at $40 \mathrm{~mA} / \mathrm{cm}^{2}$ current density and different values of etching time. The AFM is useful for obtaining two and threedimensional topographic information and the root mean square of roughness and grain size are obtained by using certain software 


\section{EXPERIMENTAL}

Porous silicon films were produced using monocrystalline silicon wafers, p-type with resistivity's ranging from (14-22) $\Omega \cdot \mathrm{cm}$. The wafers with (111) face orientation. Samples were made of porous silicon produced with a standard technique of anodizing silicon substrates in an electrolyte $\mathrm{HF}(40 \%)$ : $(99.8) \% \mathrm{CH}_{3} \mathrm{OH}$ with a volume ratio of [1:1]. The simplest cell which can be used to anodize silicon is shown in figure 1.The silicon wafer serves as the anode. The cathode is made of platinum or any HF-resistant and conducting material. The cell body itself is, in general, made of highly acid-resistant polymer such as Teflon.

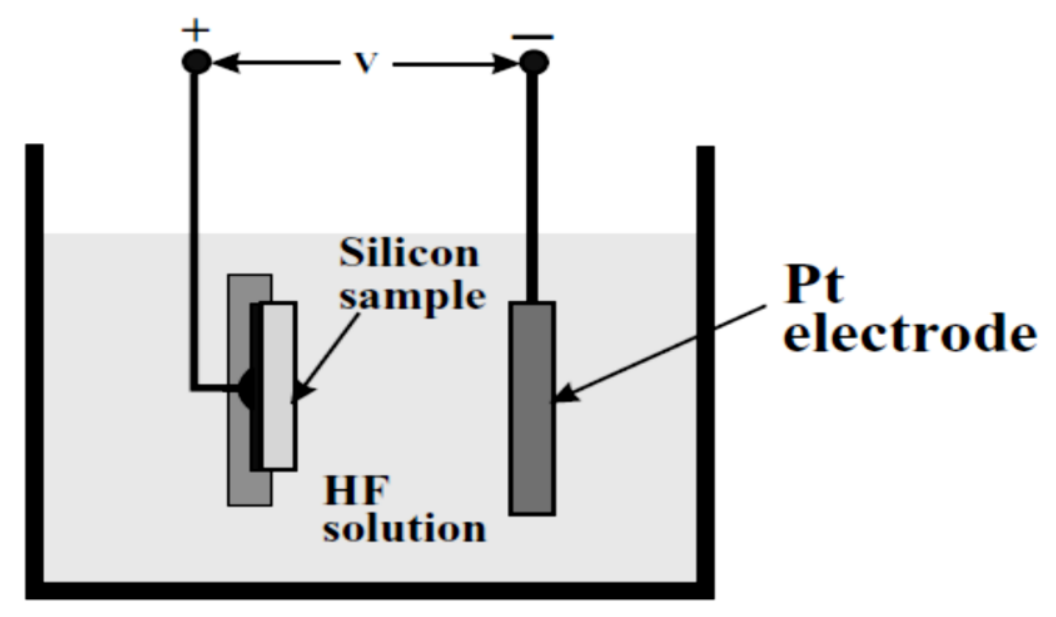

Figure 1. Schematic of the designed porous silicon fabrication system.

Cleaning is necessary to remove any traces of organic, metallic and ionic contaminants from samples. Methanol and alcohol are used commonly to clean the wafer by immersing it in these chemicals in turn in the ultrasonic bath for few minutes. Finally, they were rinsed in distilled water treated ultrasonically followed by drying in a hot air stream. Back side of the samples was coated with thick Aluminums layer. The evaporation is performed in a vacuum pressure of $10^{-6}$ torr, using an evaporation plant model "E306 A manufactured by Edwards high vacuum". In this work an AA 3000 Scanning Probe Microscope AFM system. The XRD (shimadzu -6000) system was used for x-ray diffraction measurements. They were then placed into the $\mathrm{x}$-ray $(\mathrm{Cu} \mathrm{K} \alpha 1$ line $\lambda=1.5406 \mathrm{~A})$ generating chamber under acceleration voltage of $40 \mathrm{kV}$ and a current of $30 \mathrm{~mA}$. The sample was scanned from 25 to 40 degrees 2Theta. In gravimetric method, "Mettler AE-160 digital with accuracy of $0.0001 \mathrm{mg}$ " is used to weight the samples. XRD was used to investigate the size of the crystallites of the porous silicon. The average grain size (crystallite size) corresponds to the average diameter (L) of the crystallite columns which can be calculated by using Debye-Scherrer formulas shown in following equation [2].

$$
\mathrm{L}=0.9 \lambda / \mathrm{FWHM} \cdot \cos (\theta)
$$

where the FWHM is the full width at the half maximum of the characteristic spectrum in units of radians, $\mathrm{L}$ and $\lambda$ are in $\mathrm{nm}$. 


\section{RESULTS AND DISSCUSION}

Figure 2 shows the X-ray diffraction patterns of the porous structure on $\mathrm{p}$-Si substrate at $(10,20$, and $30 \mathrm{~min})$ etching time. X-ray diffraction spectra show a distinct variation between the fresh silicon surface and the porous silicon surfaces formed at different etching times. A strong peak of (c-Si) fresh silicon shows a very sharp peak at $2 \theta=28.38^{\circ}$ oriented only along the (111) direction is observed confirming the monocrystalline structure of the $\mathrm{Si}$ layer which belongs to the (111) reflecting plane of Si of cubic structure (according to ICDD N 1997and 2011 JCPDS) as shown in table 1.

With increasing etching time, this peak becomes very broad with varying full-width at half maximum, which confirms the formation of porous structure on the crystalline silicon surface. The broadening in the diffracted peaks is due to the increasing thickness of pore walls, and upward shifts are due to relaxation of strain in the porous structure. Also The additional peak at the lower angle at $2 \theta=28.88,28.99$, and 29.27 , may be attributed to a lattice expansion of the porous layers.

The presences of this peak in all the PS structures confirm that the cubic structure of the crystalline silicon is retained even after the pore formation. This observation agrees well with [5-7]. All of the additional peaks at the lower angle have the same oriented (111) plane reflections, hence the PS layer has cubic structure. It is a unique example of a porous material exhibiting the properties of a nearly perfect single crystal.

Table 1. Calculated crystalline size, Lattice constant, and strain for p-type porous $\mathrm{Si}$ at $40 \mathrm{~mA} / \mathrm{cm}^{2}$ etching current density for different etching time.

\begin{tabular}{|c|c|c|c|c|c|c|}
\hline $\begin{array}{l}\text { Etching } \\
\text { time } \\
\text { [min] }\end{array}$ & $\begin{array}{l}\text { 2Thets } \\
\text { [des] }\end{array}$ & a) & $\begin{array}{l}\text { FWHM } \\
{[\theta t]}\end{array}$ & $\begin{array}{l}\text { Grain siz: } \\
\text { [nm] }\end{array}$ & $\begin{array}{l}\text { Lattise } \\
\text { onstent } \\
\text { [nm] }\end{array}$ & Strain \\
\hline 10 & 28.88 & 3.08 & 0.1813 & 145.6 & 5.34 & 0.0189 \\
\hline 20 & 2899 & 3.07 & 0.1733 & 129.3 & 5.32 & 0.0150 \\
\hline 30 & 29.27 & 3.04 & 0.1939 & 85.6 & 5.28 & 0.00575 \\
\hline
\end{tabular}

Two and Three-dimensional AFM image of the as-anodized porous silicon surface structure formed on p-type for different time etching (10-30) min are shown in the following figures. The PS layer thickness and roughness are not monotonically proportional to the anodization time.

The surface morphology measured by AFM is given in Figures (3-5), which show that the surface of the PS layer consists of inhomogeneous and large number of irregularly shaped distributed randomly over the entire surface.

Representative $2 \mu \mathrm{m} \times 2 \mu \mathrm{m}$ images 2 and 3 dimension of porous silicon with various etching time are shown in Figures (3-5). The surface of the etched PS layer consists of a matrix of randomly distributed nanocrystalline Si pillars which have the same direction and AFM images also show voids that the uniformity. Root-mean-square (RMS) surface roughness is a commonly accepted of parameter to describe surface. It is typically used to quantify variations in surface elevation. 


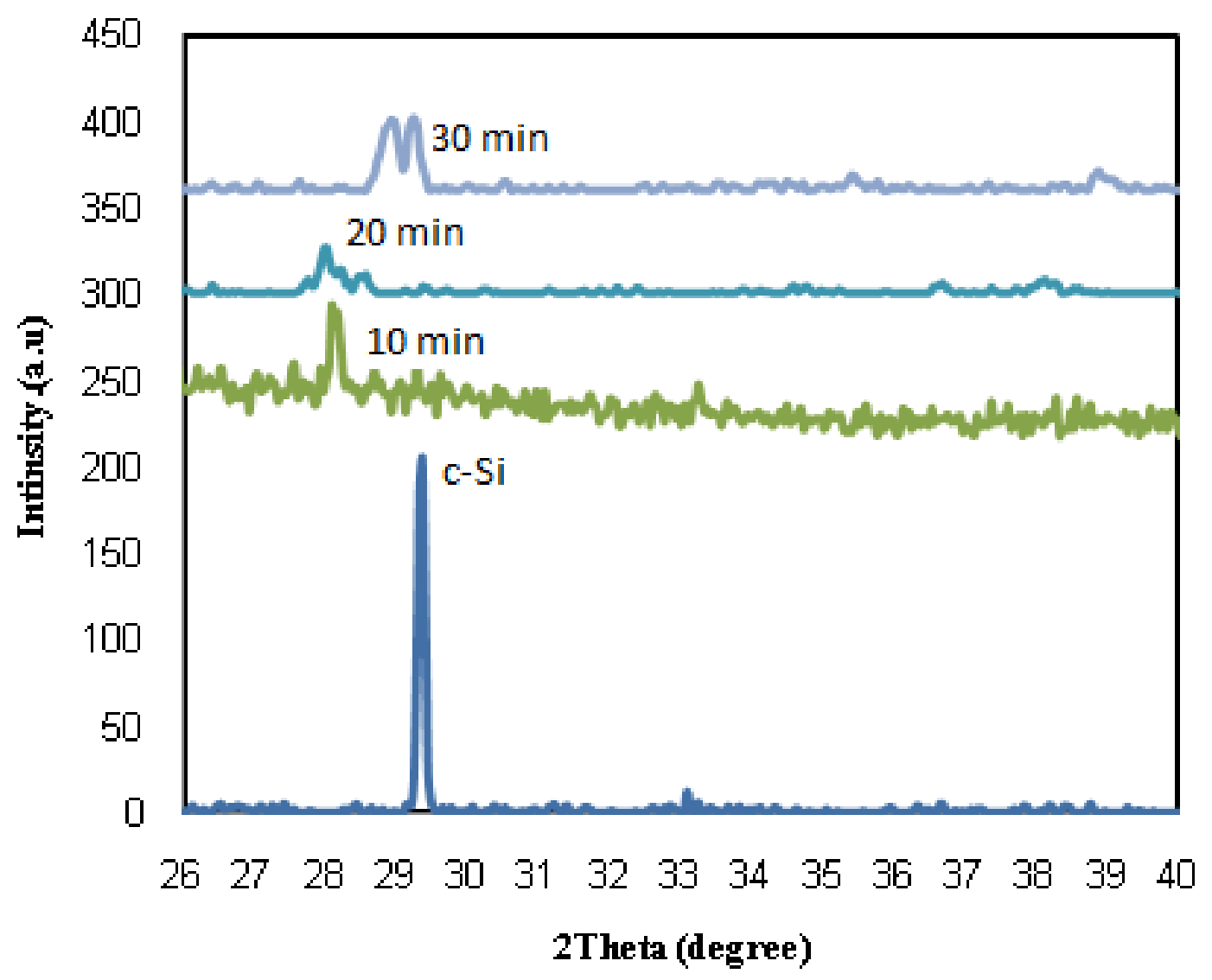

Figure 2. XRD spectra of c-Si and PS samples anodized for $40 \mathrm{~mA} / \mathbf{c m}^{2}$ etching current density at 10,20 , and 30 min etching time.

The RMS roughness for p-type is found to be 1.98-29.2 nm and Sz. (Ten Point height) from $21.4-146 \mathrm{~nm}$ as shown in Table 2 with large irregular upright structure of silicon crystallites. A change of microstructure of the porous silicon surface are observed for different etching time (10-30) min where pore sizes varied significantly as shown in the AFM picture given in figures at constant etching current density. This roughness is expected to be caused by inhomogeneous of the substrate and electrolyte composition, and seems to increase with layer thickness.

The root means square height or roughness, as we expected. Again, increases with the etching time and closed to saturate around $29.2 \mathrm{~nm}$ at higher etching time as shown in Figure 5. Porous silicon has much different structures and its pore diameter varies from nanometer to micrometer, according to the etching conditions as shown in the Figures (3-5).

The basic mechanism for the formation of porous structure is due to the charge carrier generation at semiconductor electrolyte interface by external biasing. When etching time increases, more and more numbers of carriers which take part in etching process come into the semiconductor electrolyte interface, leading to increase in the pore size, the increase in pore size leads to decrease in sizes of pore wall [8]. 

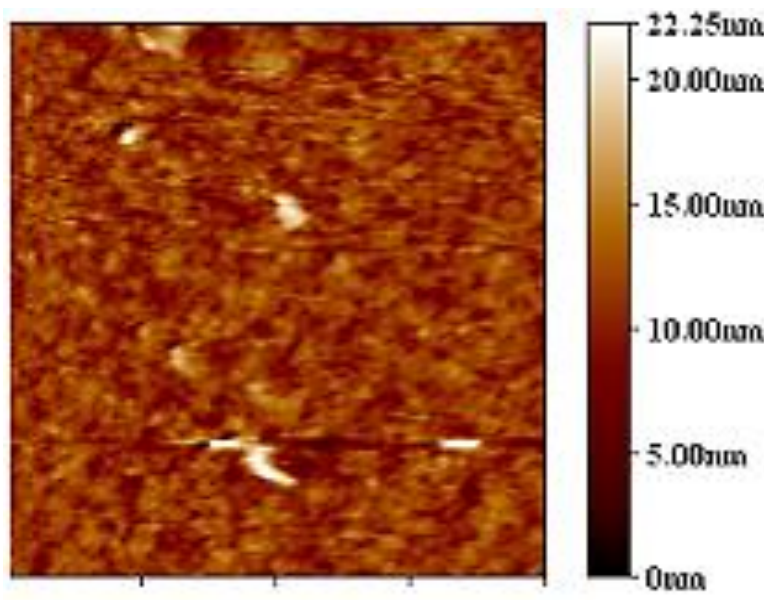

Figure 3. 2D and 3D AFM images of PS surface at constant current density $40 \mathbf{m A} / \mathbf{c m}^{2}$ and at 10 min etching time for $\mathrm{p}$-type $(2 \mu \mathrm{m} \times 2 \mu \mathrm{m})$.
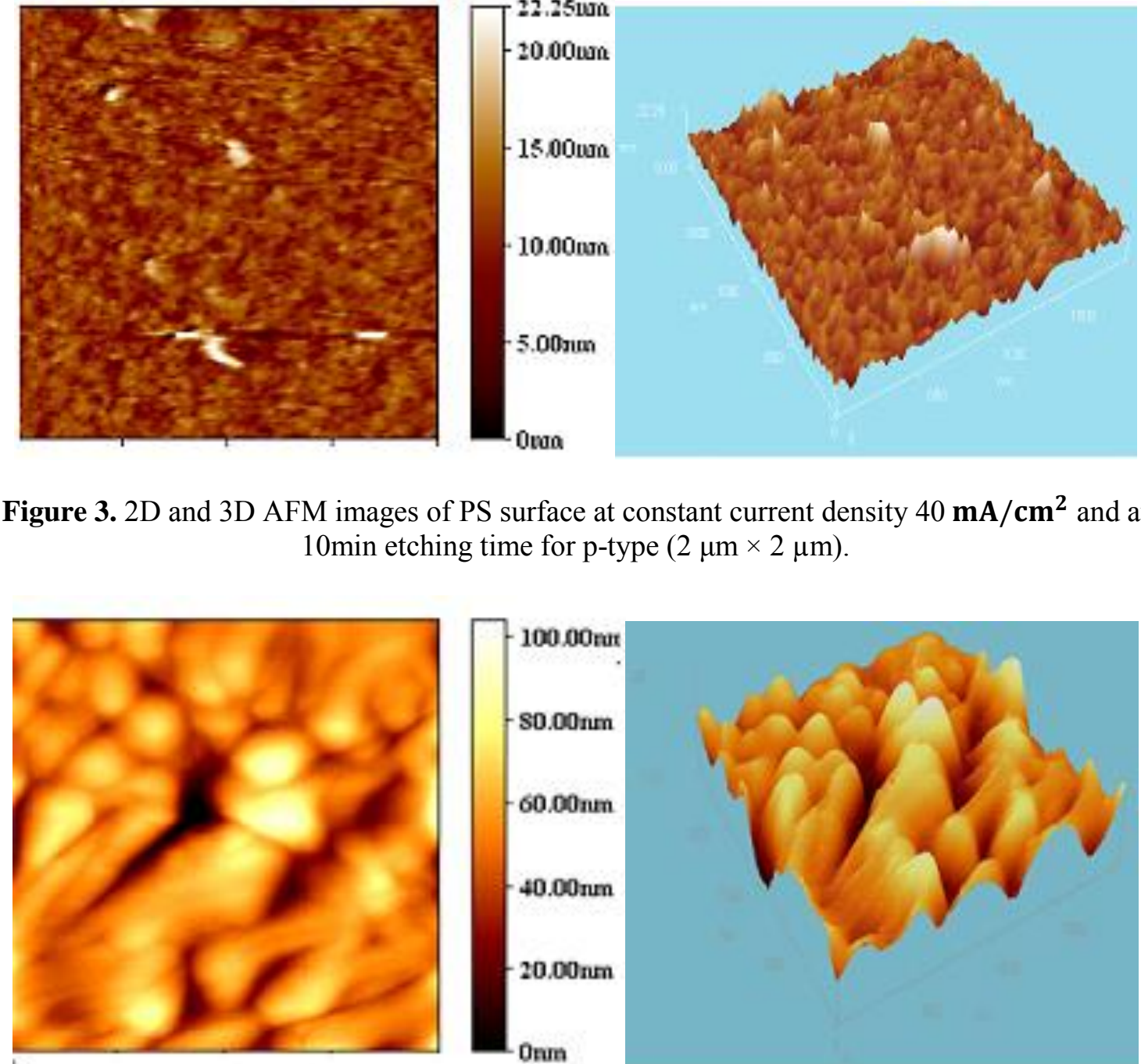

Figure 4. 2D and 3D AFM images of PS surface at constant current density $40 \mathbf{m A} / \mathbf{c m}^{2}$ and at
20min etching time for p-type $(2 \mu \mathrm{m} \times 2 \mu \mathrm{m})$.

Figure 4. 2D and 3D AFM images of PS surface at constant current den
20min etching time for p-type $(2 \mu \mathrm{m} \times 2 \mu \mathrm{m})$.
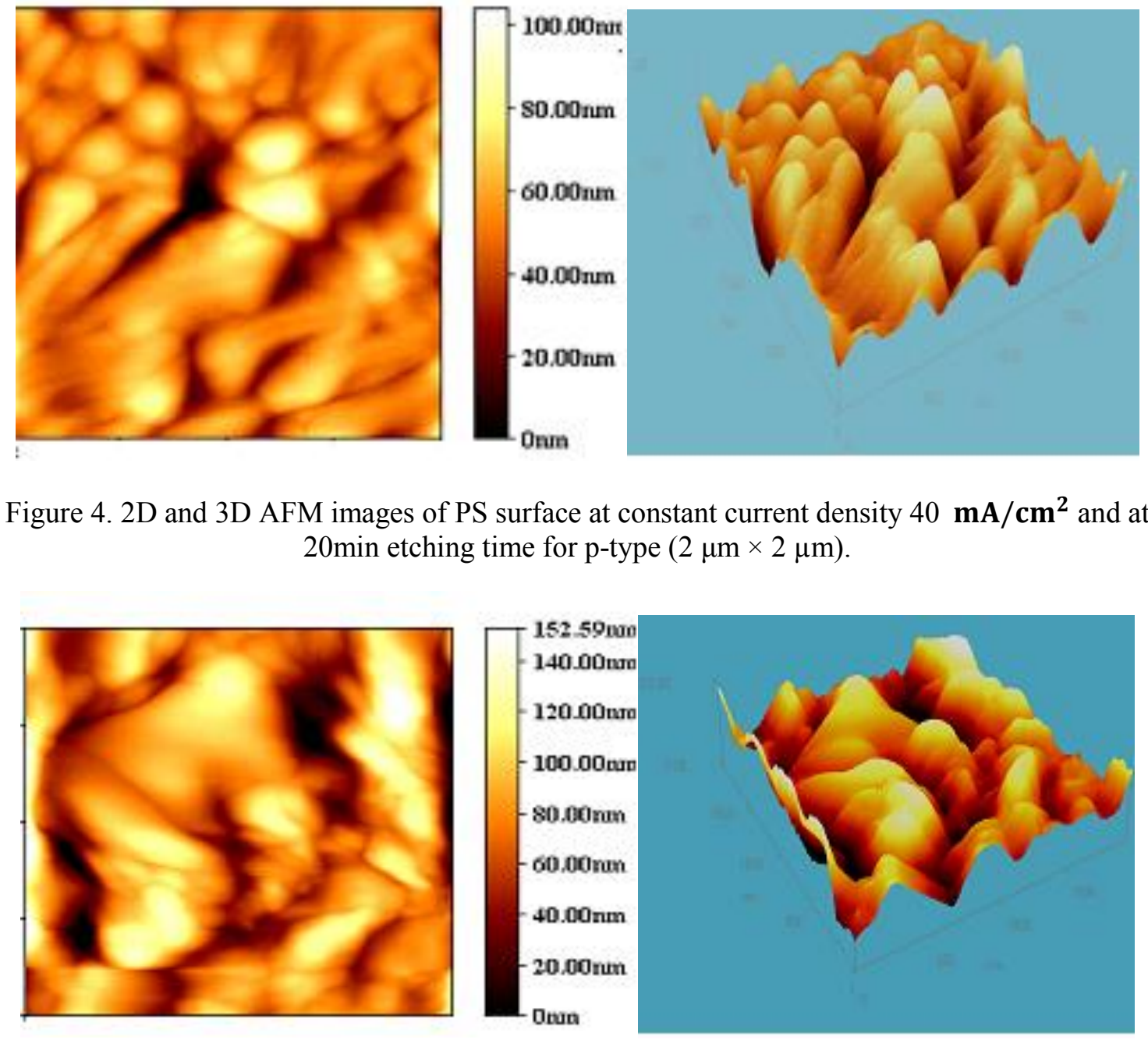

Figure 5. 2D and 3D AFM images of PS surface at constant current density $40 \mathbf{m A} / \mathbf{c m}^{2}$ and at $30 \mathrm{~min}$ etching time for $\mathrm{p}$-type $(2 \mu \mathrm{m} \times 2 \mu \mathrm{m})$. 
Table 2. The root mean square of roughness and grain size were obtained by using certain software function of etching time.

\begin{tabular}{llllll}
\hline $\begin{array}{l}\text { Etching } \\
\begin{array}{l}\text { Current } \\
\text { density }\end{array}\end{array}$ & $\begin{array}{l}\text { Time } \\
\text { anodization }\end{array}$ & $\begin{array}{l}\text { height PS } \\
\text { Layer }\end{array}$ & $\begin{array}{l}\text { Sq. } \\
\text { root } \\
\text { mean } \\
\text { square }\end{array}$ & $\begin{array}{l}\text { Sz. } \\
\text { Ten } \\
\begin{array}{l}\text { Point } \\
\text { Height }\end{array}\end{array}$ & $\begin{array}{l}\text { Avg. } \\
\text { diameter }\end{array}$ \\
$\mathrm{mA} / \mathrm{cm}^{2}$ & min & $\mathrm{nm}$ & $\mathrm{nm}$ & $\mathrm{nm}$ & $\mathrm{nm}$ \\
\hline 40 & 10 & 22.25 & 1.98 & 21.4 & 82.71 \\
\hline- & 20 & 100 & 13.4 & 96.2 & 109.45 \\
\hline- & 30 & 152.59 & 29.2 & 146 & 132.36 \\
\hline
\end{tabular}

From Tables 1 and 2 we observed disagreement in crystal size result calculated from Xray diffraction and AFM. This result can be described according to the fact that, the broadening in X-ray peak is not only due to crystal refining, but also due to the strain formed in the crystal [9].

\section{CONCLUSION}

The X-ray diffraction patterns of the porous structure on $\mathrm{p}$-Si substrate at different etching time and at constant etching current density shows unique example of a porous material exhibiting the properties of a nearly perfect single crystal. XRD spectra show the formation of porous silicon. Nanocrystals size computing from XRD data is resulting the increasing etching time. Porous silicon has much different structures and its pore diameter varies from nanometer to micrometer, according to the etching conditions as shown from the experimental results of AFM.

\section{References}

[1] Hasan A. Hadi, International Letters of Chemistry, Physics and Astronomy 17(2) (2014) 142-152.

[2] Hasan A. Hadi, Raid A. Ismail, Nadir F. Habubi, International Letters of Chemistry, Physics and Astronomy 3 (2013) 29-36.

[3] Hasan A. Hadi, Intesar H. Hashim, Journal of Electron Devices 20 (2014) 1701-1710.

[4] M. Jayachandran, M. Paramasivam, K.R. Murali, D.C. Trivedi M. Raghavan, Meter. Phys. Mech. 4 (2001) 143-147.

[5] J. P. Kar, S. K. Mothanta, G. Bose, S. Tuli, A. Kamra, V. Mathur, Journal of optoelectronic and advanced material 11 (2009) 238-242.

[6] M. Jayachandran, M. Paramasivam, K. Murali, D. Trivedi, M. Raghavan, Meter. Phys. 
Mech. 4 (2001) 143-147.

[7] K. Omar, A. Ramizy, Z. Hassan, Superlattices and Microstructures 50 (2011) 119-127.

[8] Z. Hens, D. Vanmaekelbergh, E. J. Stoffels, H. Kempen, Phys. Rev. Lett. 88 (2002) 236803.

[9] V. Parkhutik, Solid-state Electron. 43 (1999) 1121-1141. 